\title{
Necessária, mas não suficiente: sobre a função da crítica da economia na teoria crítica tardia de Theodor W. Adorno*
}

\author{
Necessary, but not sufficient: on the role of the critique of economy \\ in Theodor W. Adorno's late critical theory
}

\author{
Amaro Fleck \\ amarofleck@hotmail.com \\ (Universidade Federal de Lavras, Minas Gerais, Brasil)
}

\begin{abstract}
Resumo: Diversos intérpretes da obra de Theodor W. Adorno sugerem que a crítica da racionalidade instrumental substituiu a crítica do capitalismo no desenvolvimento de sua obra, principalmente por causa da adoção do diagnóstico acerca do surgimento do capitalismo de Estado proposto por Friedrich Pollock. Neste artigo questiono a aceitação por parte de Adorno, ao menos em sua obra tardia, de tal diagnóstico e mostro que a crítica do capitalismo não foi substituída pela crítica da razão, e sim complementada.
\end{abstract}

Palavras-chave: Theodor W. Adorno; teoria crítica. capitalismo tardio; crítica da razão.

\begin{abstract}
Many different interpreters of Theodor W. Adorno's work suggest that the critique of instrumental rationality has replaced the critique of capitalism in the development of his work, mainly because of the adoption of the diagnosis about the emergence of state capitalism, which was proposed by Friedrich Pollock. In this paper, I question the acceptance by Adorno, at least in his later work, of such diagnosis and show that the critique of capitalism was not replaced by the critique of reason, but complemented by it.
\end{abstract}

Keywords: Theodor W. Adorno; critical theory; late capitalism; critique of reason.

DOI: http://dx.doi.org/10.11606/issn.2318-9800.v21i2p13-29

No começo dos anos 1940, com a ascensão do nazifascismo na Europa, com as políticas anticíclicas keynesianas nos Estados Unidos e com o aparente sucesso do planejamento econômico soviético, os teóricos vinculados ao Instituto de Pesquisa Social, então exilado na América do Norte, perceberam a necessidade de teorizar as profundas transformações então em curso na organização econômica das sociedades ocidentais.

No conhecido ensaio programático de 1937, "Teoria tradicional e teoria crítica”, Horkheimer sugeria que a principal diferença entre o capitalismo tardio ou monopolista de então frente ao capitalismo liberal, investigado por Marx setenta anos

\footnotetext{
* O presente artigo é uma versão modificada de um capítulo de minha tese de doutorado, intitulada "Theodor W. Adorno: um crítico na era dourada do capitalismo", defendida na UFSC em 2015. A tese foi orientada pelo Prof. Alessandro Pinzani, a quem agradeço.
} 
antes, era que agora os meios de produção estavam nas mãos de magnatas industriais, ao passo que antes quem detinha o capital e o controle sobre ele eram os pequenos proprietários privados (Cf. Horkheimer, 1975, pp.157-8) ${ }^{1}$. Quatro anos depois, no entanto, Pollock publicava na revista do Instituto os artigos "State Capitalism" e "Is National Socialism a New Order?”, nos quais sugeria que a mudança então em curso alterava a ordem social em um nível muito mais fundamental. Com a ascensão do planejamento e do Estado interventor, Pollock afirmava que a dominação econômica típica do século dezenove havia se transformado em uma dominação eminentemente política. Esta transformação, de acordo com grande parte da literatura secundária sobre o Instituto e seus teóricos, teria causado alterações de grande monta nas análises subsequentes, levando a um abandono da crítica ao capitalismo e à economia política, ou melhor, a uma substituição desta pela crítica da dominação da natureza e da racionalidade instrumental - e tal substituição seguiria vigente nas obras posteriores de todos os teóricos críticos da assim chamada "primeira geração".

No entanto, como mostrarei a seguir, é um engano acreditar que Adorno, ao menos em suas obras tardias ${ }^{2}$ (sobretudo aquelas dos anos 1960), aderiu à tese de Pollock. E mais: é um equívoco supor que as críticas da economia política e do capitalismo deixaram de estar no centro de sua análise. A hipótese que defendo, por conseguinte, é que, ao menos de acordo com o Adorno tardio (mas não, necessariamente, com outros teóricos críticos do Instituto $^{3}$ ) a crítica do capitalismo seguiu sendo necessária, mas já não era mais suficiente. Com as mudanças então em curso, o pensamento crítico não podia mais se limitar a criticar o capitalismo deixando de lado as reflexões acerca de quanto o próprio capitalismo se imiscuiu na forma de racionalidade prevalecente e faz uso desta para seus propósitos; tampouco podia deixar de lado a questão da dominação da natureza, nem, ainda, ignorar os danos e as mutilações sofridas pelo indivíduo ou pelo que restava dele.

No presente artigo devo analisar com maior atenção a argumentação de Pollock (I); para, então, apresentar a interpretação hegemônica acerca da obra tardia de

1 Convém ressaltar que "Teoria tradicional e teoria crítica" já apresenta o começo desta transformação teórica que visa repensar a crítica social a partir do advento do nazifascismo e das transformações econômicas então em curso. Neste texto, inclusive, surgem os primeiros questionamentos acerca do quanto a própria forma de racionalidade moderna estaria imbricada com a realidade capitalista criticada, de forma que a crítica social passaria a ser também uma crítica do conhecimento. A este respeito, cf. Berendzen, 2013.

2 Uma investigação maior sobre a função da crítica da economia e do capitalismo que foque sobre a obra produzida antes, especialmente na década de 40 , demandaria uma nova pesquisa ou uma ampliação da presente que ultrapassaria os limites do que pode ser abordado de forma razoável na extensão de um artigo. No entanto, não creio que isto que defendo sobre a obra da década de 60 - a saber, que o diagnóstico de época nela presente segue concedendo uma função crucial para a economia, e que a dominação econômica seguiria tendo primazia sobre a dominação política - não possa ser também defendida para a década de 1940.

3 Não afirmo, com isso, que a centralidade da crítica ao capitalismo seja exclusividade de Adorno no interior da teoria crítica. 
Adorno, a qual sugere a tese da adesão ao diagnóstico de Pollock e da substituição do objeto da crítica (II); a seguir, mostro as principais deficiências de tal interpretação e demonstro, a partir de um número significativo de passagens, que Adorno, ao menos em sua obra tardia, não aderiu à posição de Pollock e que não houve uma substituição do objeto de crítica (III); por fim, argumento que, especificamente na teoria crítica tardia proposta por Adorno, a crítica da economia política, embora seguisse sendo necessária, já não era mais suficiente para criticar a vida danificada que se vivia, então, nas sociedades ocidentais (IV). Embora o foco do artigo esteja nos escritos, nas conferências e nos cursos da década de 1960 do autor frankfurtiano (momento este a que designo como período tardio de seu pensamento), eventualmente menciono passagens de obras anteriores ou faço alusão a argumentos presentes nelas.

\section{Pollock e a tese do capitalismo estatal}

Embora Pollock fosse, por assim dizer, o principal economista do Instituto, o seu tesoureiro e um dos membros mais influentes nas tomadas de decisão, a sua obra foi relativamente marginal e se restringiu, grosso modo, à publicação de alguns artigos na revista do Instituto ${ }^{4}$. Se, de um ponto de vista meramente quantitativo esta contribuição teórica corre o risco de ser menosprezada, ela provocou não só uma das maiores cisões teóricas internas na teoria crítica como influenciou de forma profunda os novos diagnósticos de época que foram feitos a partir de então. Os artigos de 1941 sugeriam que as mudanças em curso eram bem mais profundas do que Horkheimer propusera no escrito "Teoria tradicional e teoria crítica”, pois de acordo com eles o capitalismo não teria passado de sua fase liberal para a fase tardia ou monopolista, mas sim de uma fase privada para sua fase estatal, mudança esta que alterava o próprio caráter da dominação. Estes artigos, portanto, dizem respeito a como se deve entender esta nova fase, a do capitalismo estatal ${ }^{5}$.

De acordo com Pollock, é questionável se o capitalismo estatal existe ou mesmo se poderia existir, mas mesmo assim se pode falar dele como um modelo, como se fosse um "tipo ideal" weberiano. Este tipo ideal serviria para designar a

\footnotetext{
4 Mais precisamente quatro artigos, "Die gegenwärtige Lage des Kapitalismus und die Aussichten einer planwirtschaftlichen Neuordnung" [numa tradução livre: "A situação atual do capitalismo e a expectativa de uma nova ordem econômica planificada"], em 1932, "Bemerkungen zur Wirtschaftskrise" ["Observações sobre a crise econômica"], em 1933, e os dois artigos de 1941 já mencionados. Para uma análise do percurso teórico de Pollock, cf. Marramao, 1975 e Postone, 2003, cap. 3.

50 termo "capitalismo de Estado" não foi cunhado por Pollock. Este já era um termo bastante usado (por exemplo, por Bukharin (1972, Cap. 13)) para se referir ao novo estágio do capitalismo, marcado precisamente pelo aumento da interferência estatal. Lênin usou o mesmo termo, de forma positiva, como um momento necessário na transição ao socialismo então em curso na União Soviética. A especificidade do emprego do termo por Pollock é a tese de que o capitalismo de Estado é caracterizado pela primazia do político sobre o econômico.
} 
direção para a qual estão se orientando as transformações da sociedade, em especial as europeias, mas aparentemente também a norte-americana e mesmo a soviética. Ademais, ele não é um conceito unívoco, uma vez que o capitalismo estatal pode se dar em diversas formas intermediárias entre dois extremos, o totalitário, tal como existe na Alemanha governada pelos nazistas, e o democrático, do qual "nossa experiência nos dá poucos indícios" (Pollock, 1941, p.200), mas que poderia se desenvolver nas novas condições econômicas.

Mas o que é “capitalismo estatal"? Segundo Pollock, este não deve ser entendido como um termo que designa a sociedade na qual o Estado é o único proprietário dos meios de produção ou de todo o capital, mas sim um que indica quatro características: "que o capitalismo estatal é o sucessor do capitalismo privado, que o Estado assume funções importantes do capitalista privado, que o interesse pelo lucro ainda possui um papel significante, e que este não é socialismo" (Pollock, 1941, p.201). O importante a salientar é que o mercado, no modelo de capitalismo estatal delineado, não tem a função de coordenar a produção e a distribuição, o que passa a ser feito por um sistema de controle direto: “liberdade de comércio, empresa e trabalho são sujeitos à interferência governamental em tal grau que são praticamente abolidos” (idem, p.200). Ou, mais precisamente:

Concentração da atividade econômica em empresas gigantes, com suas consequências de preços rígidos, autofinanciamento e crescente concentração, controle governamental do sistema de crédito e do comércio exterior, posições de quase monopólio das uniões de comércio com a subsequente rigidez do mercado de trabalho, desemprego do capital e do trabalho em larga escala e enorme gasto governamental para cuidar dos desempregados, são como sintomas para o declínio do sistema de mercado (idem, p.202).

Assim sendo, no caso da forma totalitária do capitalismo estatal (a Alemanha nazista) há um novo grupo governante, formado pela elite da administração industrial e de negócios, da burocracia estatal (inclusive militar) e pelos líderes do partido vitorioso. Quem não pertence a este seleto grupo torna-se "mero objeto de dominação" (Pollock, 1941, p.201). Já no caso da forma democrática, o Estado é controlado pelo povo e está baseado em instituições que previnem "a burocracia de transformar sua posição administrativa em um instrumento de poder” (idem, p.202).

Tanto no caso democrático como no autoritário, no capitalismo estatal tudo segue um planejamento central que direciona a produção, o consumo, a poupança e o investimento. Isto causa mais uma importante distinção frente à fase do capitalismo monopolista liberal ou privado que o antecede:

o problema genuíno de uma sociedade planejada não está na esfera econômica, mas na política, nos princípios a serem aplicados ao decidir que necessidades devem ter preferência, quanto tempo deve ser despendido para o trabalho, quanto do produto social deve ser consumido e quanto usado para expansão etc. (Pollock, 1941, p.204). 
Além disso, "o interesse de lucro tanto de indivíduos quanto de grupos, assim como todos os outros interesses especiais são estritamente subordinados ao plano geral" (idem, p.205). Ao contrário do que ocorre no capitalismo privado, "o interesse do grupo dominante como um todo é decisivo, não o interesse individual daqueles que formam o grupo" (idem, ibidem). Assim, a transição do capitalismo privado para o capitalismo estatal é a transição de "uma era predominantemente econômica para uma essencialmente política" (idem, p.207), sendo "o estímulo do lucro superado pelo estímulo do poder" (idem, ibidem). Desta forma, cria-se um sistema econômico planejado e regulado pelo governo que não está mais sujeito às leis econômicas: "o controle governamental da produção e da distribuição fornece os meios para eliminar as causas econômicas das depressões, processos destrutivos cumulativos e desemprego do capital e do trabalho" (idem, p.217).

Em resumo, Pollock caracteriza o capitalismo estatal como uma nova fase da organização social que segue sendo capitalista, portanto, em que segue havendo uma produção voltada para o ganho, para o lucro, mas na qual o estímulo do lucro é subordinado ao estímulo do poder, em que as relações políticas passam a ter a primazia, subordinando as relações econômicas e em que, por fim, as contradições do sistema capitalista são atenuadas pelo planejamento central até se tornarem praticamente insignificantes.

\section{Capitalismo estatal e substituição do objeto de crítica}

Para dizer o mínimo: a tese de Pollock era demasiado polêmica. Ainda mais para teóricos simpáticos ao marxismo e, por conseguinte, à ideia de que a dominação econômica era o que caracterizava o capitalismo como tal. O que Pollock estava propondo era nada menos do que uma reformulação radical do diagnóstico de Marx: a nova ordem social teria conseguido estabilizar as contradições sistêmicas que conduziam o capitalismo à crise, de tal maneira que a forma de dominação deixara de ser econômica para passar a ser política. O pensamento emancipatório poderia deixar de se orientar pelo ideal socialista, cuja característica essencial, para Pollock, consistia na propriedade coletiva dos meios de produção, para passar a almejar uma forma de capitalismo estatal democrático, em que o controle (e não a propriedade) dos meios de produção estaria nas mãos do povo.

A tese, é desnecessário dizer, não ganhou adesão automática por parte dos frankfurtianos exilados. Ela era radicalmente oposta, por exemplo, à interpretação de Neumann acerca do fascismo. Neumann sugeria que o fascismo não era uma ordem coesa e planejada, como pensava Pollock, mas sim uma espécie de guerra de todos contra todos em que os poderes competiam entre si, mas no qual a economia e o motivo do lucro seguiam tendo a primazia. Em seu livro Behemoth, Neumann 
afirma que "o próprio termo 'capitalismo estatal' é uma contradictio in adjecto" (Neumann, 2009, p.224) 6 . Mas Pollock teve, de forma quase imediata, a simpatia de Horkheimer, que já em seu artigo de 1942, "The Authoritarian State", declara que "o capitalismo estatal é o Estado autoritário do presente” (Horkheimer, 1985, p.96).

A hipótese da adoção da tese do capitalismo estatal também por parte de Adorno se torna por isso sedutora, uma vez que precisamente neste período ele e Horkheimer se aproximam, passando inclusive a redigir, em conjunto, a Dialética do esclarecimento. Ademais, como tal livro está centrado numa reflexão acerca da perversão do esclarecimento, e não (imediatamente) na denúncia da dominação econômica ${ }^{7}$, tal hipótese pode parecer bastante atraente. De fato, é isto que sugere Martin Jay, em seu muito influente livro A Imaginação dialética, uma das primeiras monografias (foi publicada em 1973) inteiramente dedicadas à teoria crítica. Apesar de focar apenas nas três primeiras décadas do Instituto (isto é, sua fundação, seus primeiros anos na Alemanha e seu período de exílio), Jay retrata um panorama do desenvolvimento teórico da teoria crítica que se tornou predominante e está presente em grande parte da literatura que versa sobre a obra de Adorno. Em tal livro, Jay sugere que há uma ruptura entre a obra inicial dos frankfurtianos e a obra tardia causada, sobretudo, por três fatores, fortemente entrelaçados. Segundo Jay:

a) O Século XX, ao contrário do Século XIX, se caracteriza por uma "primazia do político", e não por uma primazia do econômico. Esta tese é sustentada por Friedrich Pollock em seu conhecido artigo sobre o capitalismo estatal e teria sido aceita por Adorno, Horkheimer e outros membros do Instituto, exceção feita a Franz Neumann (cf. Jay, 2008, pp.168-9, 205-9).

b) Ao longo da década de 1940, há uma paulatina substituição do objeto criticado pela teoria crítica: as relações sociais do capitalismo cedem cada vez mais espaço à "relação subjacente entre homem e a natureza" (Jay, 2008, p.318). Mais precisamente:

A expressão mais clara dessa mudança foi a substituição que o Institut fez do conflito entre classes, pedra angular de qualquer teoria verdadeiramente marxista, por um novo motor da história. $\mathrm{O}$ foco passou a incidir sobre o conflito maior entre o homem e a natureza, tanto externa quanto internamente - um conflito cuja origem remontava a uma época anterior ao capitalismo e cuja continuação, ou até intensificação, parecia provável depois que o capitalismo chegasse ao fim (Jay, 2008, p.321).

c) Tal substituição também leva a um abandono da práxis transformadora.

6 Sobre a interpretação do fascismo feita por Neumann, conferir Ramos, 2013.

7 Apesar de ser a obra mais comentada de Adorno, é preciso notar que falta uma análise de maior fôlego acerca do papel da economia no diagnóstico traçado nela. Isto porque a crítica ao capitalismo não é tão secundária como pode parecer, sobretudo nos ensaios sobre a indústria cultural e sobre o antissemitismo, além de ser um dos principais motivos, senão mesmo o principal, a causar a perversão do esclarecimento. 
Com o deslocamento da ênfase do Institut da luta de classes para o conflito entre o homem e a natureza, a possibilidade de um sujeito histórico capaz de introduzir a época revolucionária desapareceu. Aquele imperativo da práxis (...) deixou de ser parte integrante de seu pensamento (Jay, 2008, p.345).

Assim, a conclusão de Jay é que o Instituto de Pesquisa Social se transformou, ao longo da década de 1940, afastando-se do radicalismo que marcara sua primeira fase $^{8}$ e distanciando-se cada vez mais do marxismo que the servira de mote em seus primórdios, a tal ponto que no fim ele "apresentou uma revisão tão substancial do marxismo, que renunciou ao direito de ser incluído entre suas muitas ramificações” (Jay, 2008, p.363) ${ }^{9}$. Infelizmente, no entanto, Jay não explica como a mudança do objeto de crítica ocorre, nem pormenoriza a influência de Pollock sobre Adorno em especial, tratando todos aqueles que denomina como "círculo interno" do Instituto em bloco. Embora não trate especificadamente da obra tardia de Adorno, é evidente que a mudança analisada por Jay diz respeito também a tal obra e período, uma vez que ela circunscreve o campo em que o Instituto vai se desenvolver no retorno à Alemanha, momento em que, notadamente, Adorno passa a ocupar um papel cada vez mais proeminente nele ${ }^{10}$.

É quase desnecessário mostrar quão presente estão tais hipóteses no restante da literatura que trata da obra adorniana. A começar pela interpretação de Habermas e daqueles que seguem as linhas gerais de sua exegese acerca da assim chamada "primeira geração" da teoria crítica (Wellmer, Menke, Benhabib, Honneth), que

8 Jay chega até mesmo a afirmar que Adorno e Horkheimer teriam deixado de ser "de esquerda" em dois momentos distintos: "Um abismo cada vez maior começou a separar Horkheimer e Adorno, de um lado, e Marcuse, cujas inclinações políticas se mantiveram firmemente à esquerda" (Jay, 2008, p.355) e "Assim, de certo modo, a Escola de Frankfurt concordava em que a dicotomia esquerda-direita, pelo menos tal como encarnada nas estruturas políticas em vigor, já não era relevante" (idem, p.313). Discordo de tal interpretação. A obra de Adorno está repleta de signos que a identificam claramente à esquerda no âmbito político: o combate à pobreza e ao sofrimento socialmente causado; a ênfase de que a justiça está ligada a satisfação das necessidades (contra visões meritocráticas); a crítica da desigualdade social. Neste ponto fica visível a mal sucedida tentativa de Jay de aproximar o pensamento adorniano das correntes pós-modernistas, estas sim que não se pautam mais pela dicotomia esquerda-direita. Para uma crítica de tal aproximação, cf. Dews, 1996. Na Teoria estética, por sinal, Adorno sugere que a mentalidade avançada na política significa, necessariamente, ser de esquerda: "Durante a Primeira Guerra e antes de Stalin, as convicções avançadas na arte e na política iam juntas; quem então começou a existir desperto pensa que a arte é, a priori, o que ela historicamente de modo algum era: politicamente de esquerda" (Adorno, 1986, pp.376-7).

9 Embora adote um tom crítico incisivo em sua resenha sobre o livro de Jay, Kellner em momento algum questiona a adoção do diagnóstico de Pollock nem a questão da substituição do objeto da crítica. Na verdade, sua crítica é que o contraste entre a teoria crítica dos anos 1930, em sua opinião radical, marxista e revolucionária, e a teoria crítica subsequente, quietista e resignada, quando não mesmo reacionária (caso, segundo Kellner, de Horkheimer depois do exílio), teria sido atenuada por Jay. Cf. Kellner, 1975.

10 Em outro livro, porém, Jay afirma que não há uma ruptura na obra de Adorno que permita se falar de um jovem Adorno em oposição a um Adorno tardio (Cf. Jay, 1988, p.54) e insiste na importância do marxismo heterodoxo (de Lukács e Korsch) na formação de seu pensamento (cf. idem, p.17). 
salientam e mesmo exageram todos estes três pontos ${ }^{11}$. Assim, lê-se na Teoria do agir comunicativo, por exemplo, que segundo Adorno e Horkheimer

a razão instrumental é concebida em termos das relações entre sujeito e objeto. A relação interpessoal entre sujeito e sujeito, determinante para o modelo das trocas, não tem importância constitutiva para a razão instrumental (Habermas, 2012, p.652).

Isto é, grosso modo, que Adorno e Horkheimer teriam regredido de uma concepção intersubjetiva para o paradigma da consciência, o qual concebe o mundo principalmente em termos da relação do sujeito (o homem, a humanidade) com seu outro (a natureza), em vez de pensá-lo como resultado da interação humana. Ademais, ele também menciona que Adorno e Horkheimer deixam de conceber a reificação como um fenômeno específico do capitalismo para lidar com categorias mais profundas, em especial, que a razão instrumental e o pensamento identificador são algo bem mais abrangente do que a abstração da troca mercantil ("a abstração da troca, nesse sentido, não é senão a forma histórica sob a qual o pensamento identificador atua na história mundial e determina as formas de circulação da sociedade capitalista" [Habermas, 2012, p.651]).

\section{Seria esta uma boa interpretação?}

A hipótese de que Adorno adotou a tese do capitalismo estatal e de que tal adoção acarretou uma mudança no objeto da crítica e uma guinada pessimista se tornou hegemônica na literatura que versa sobre a sua obra. A lista de comentadores que defendem tal hipótese inclui as outras obras de referência acerca da história do Instituto, como Theory and Politics, de Dubiel (1985) e The Frankfurt School, de Wiggershaus (1995). Marramao (1975), Benhabib (1986), Cohn (1986), Honneth (1993), Nobre (1998) e Postone (2003) dão central importância a tal adesão, citada ainda por Hammer (2006) e Bohman (2013). Evidentemente, há diferenças na forma como estes autores interpretam o desenvolvimento da teoria crítica, e isto não passa incólume sobre a possível influência dos artigos da década de 1940 de Pollock sobre a obra posterior adorniana; no entanto, todos eles parecem concordar quanto ao principal: a tese acerca da primazia do político sobre o econômico. Mas nem toda unanimidade é sábia ${ }^{12}$. Em primeiro lugar, corre-se o risco de projetar na obra de

11 Há uma diferença crucial entre as leituras de Jay e de Habermas. Jay não é nada crítico acerca destas transformações, na verdade, são justamente elas que tornariam a teoria crítica algo interessante para ele que, em geral, não é nada simpático a Marx ou ao marxismo. Para Habermas, ao contrário, tais mudanças teriam conduzido um projeto teórico interessante em direção a aporias sem fim, ao pessimismo resignado, por isso o tom eminentemente crítico do comentário habermasiano. Cabe notar, porém, que a retomada da teoria crítica por Habermas não consiste num retorno ao marxismo dos anos trinta, mas é ela mesma inteiramente baseada na ideia da primazia do político sobre o econômico.

$12 \mathrm{Na}$ verdade há importantes exceções a tal interpretação. Cook (2004, p.16) afirma que Adorno 
Adorno a sombra do percurso desenvolvido por Horkheimer. De acordo com boa parte da literatura que versa sobre o assunto, há um processo contínuo de desengajamento e perda da radicalidade que percorre a obra de Horkheimer, em parte devido a um gradual afastamento de Marx e do marxismo. Mas o mesmo não ocorre, de forma alguma, com a obra de Adorno. Não há menos Marx em suas obras tardias. Pelo contrário, a presença do autor de $O$ Capital é mais visível nestas do que em seus primeiros escritos. Tampouco há menos radicalidade, apesar de toda dúvida que paira na obra adorniana sobre qualquer possibilidade real de transformação social (seja em suas primeiras obras, seja em suas derradeiras).

Mas este é apenas o primeiro dos problemas que precisariam ser enfrentados. O segundo é a completa ausência de indícios, na obra de Adorno, que justifiquem tal interpretação. Adorno não adota o termo capitalismo estatal, e quando usa tal termo o faz de maneira negativa. Para começar, Adorno escreveu suas impressões sobre o manuscrito do artigo de Pollock em uma carta dirigida para Horkheimer, em junho de 1941. Nela, Adorno fala que o artigo em questão parece uma inversão da obra de Kafka; se o autor de 0 Processo retratara a hierarquia de escritórios como o inferno, Pollock retratava o próprio inferno como uma hierarquia de escritórios. Mas sua objeção mais séria consistia no questionamento acerca de se "uma economia não antagonista seria possível em uma sociedade antagonista" (Adorno e Horkheimer, 2003, p.139) ${ }^{13}$.

Adorno faz pouquíssimas menções ao termo "capitalismo estatal" em sua obra. Na Dialética negativa, para dizer que Marx e Engels não confundiram economia planejada com capitalismo de Estado (Cf. Adorno, 2009, p.268). Num trecho suprimido (Das Schema der Massenkultur) da Dialética do esclarecimento, para dizer que a própria história, tal como o indivíduo, torna-se um costume no qual se

adotou o diagnóstico de Pollock como uma descrição hábil do nacional-socialismo, mas que teria recusado qualquer generalização de tal diagnóstico para o restante do capitalismo tardio. Esta tese, no entanto, esbarra na seguinte afirmação de Adorno: "Em sua obra Behemoth, que até hoje ainda considero a melhor apresentação socioeconômica do fascismo, o falecido Franz Neumann mostrou que justamente sob o fascismo essa integração [da sociedade] é uma situação superficial, e que sob a tênue capa do Estado totalitário se trava um combate quase arcaico e anárquico entre os diversos grupos sociais" (Adorno, 2008, p.130). A explicação de Neumann era inteiramente oposta às teses de Pollock, de forma que mesmo para tal sociedade o termo capitalismo estatal seria equívoco. Pedroso $(2009,2013)$ e Zuidervaart (2011) afirmam que Adorno rejeitou a argumentação de Pollock, com o que estou de acordo. Freyenhagen (2013) e Benzer (2011) não comentam diretamente o assunto, mas ressaltam a importância da crítica ao capitalismo em toda a obra de Adorno.

130 ensaio de Adorno "Reflexões sobre a teoria das classes", de 1942, é particularmente interessante por estar temporalmente próximo do de Pollock e lidar em grande medida com os mesmos assuntos. A tese defendida no ensaio (que só foi publicado postumamente) diz que houve grandes transformações na estrutura das classes, de modo que segue havendo opressão e exploração, mas os oprimidos já não se experimentam mais como classe. Por conseguinte, tal ensaio é mais um exemplo do que estou afirmando: Adorno nota que o diagnóstico de Marx já não é mais inteiramente válido, mas as transformações por ele observadas levam a um diagnóstico bastante distinto daquele delineado por Pollock em 1941. 
esconde "a fria modernidade do monopólio e do capitalismo estatal" (Adorno, 1997, p.316). Este segundo trecho é o único no qual usa o termo para descrever a situação vigente, mas se trata de um trecho suprimido, não publicado pelos autores. Por fim, o termo reaparece no ensaio sobre o livro Admirável mundo novo, de Aldous Huxley, contido em Prismas. Neste, Adorno usa o termo "capitalismo estatal” para descrever a distopia huxleyana:

um sistema de classes racionalmente organizado e de dimensão planetária, de um capitalismo de Estado totalmente planificado, onde coletivização total corresponde à dominação total, e onde a economia monetária e a busca do lucro continuam existindo (Adorno, 1998, p.94).

Destarte, parece que o modelo delineado por Pollock pode ser aplicado à sociedade descrita no livro de Huxley.

Seria possível supor que embora não adotasse literalmente o termo "capitalismo estatal" Adorno teria usado outro conceito com o mesmo teor. Nobre e Marin (2012, p.105) sugerem que é precisamente isto o que ocorre, e que o termo adotado é o de "mundo administrado"; já Honneth (1993, p.73) afirma que o termo escolhido é o de “capitalismo tardio". o critério para mostrar que tais interpretações não sucedem é simples, basta mostrar que Adorno não defende a tese do primado do político sobre o econômico, a ideia central do argumento de Pollock. Encontrar passagens na obra de Adorno que afirmem que a dominação segue sendo eminentemente econômica exige o abandono de tal hipótese interpretativa e a sugestão de uma interpretação alternativa para a obra tardia de Adorno. Tais passagens são encontradas em abundância. Isto é, há inúmeras passagens em que Adorno defende explicitamente o contrário da tese principal de Pollock, a saber: que, apesar das grandes mudanças que ocorreram na sociedade capitalista, continua havendo um predomínio da esfera econômica, que os homens seguem sendo dominados principalmente por meio do processo econômico. Em Minima Moralia, ele fala acerca do "absoluto predomínio da economia” [absolute Vorherrschaft der Ökonomie] (Adorno, 1992, §36). Anos depois, no verbete "Sociedade", escrito um ano antes da publicação da Dialética negativa, Adorno declara:

O primário é o lucro. (...) Na redução dos homens a agentes e suportes do intercâmbio de mercadorias se oculta a dominação dos homens sobre os homens. Isto segue sendo verdade apesar de todas as dificuldades com as que, entretanto, viram-se confrontadas algumas categorias da crítica da economia política. A estrutura total da sociedade tem a forma pela qual todos tem de submeter-se à lei de intercâmbio se não quiserem sucumbir, independentemente se subjetivamente se veem guiados ou não por um “estímulo de lucro”. (Adorno, 1986b, p.13).

Em “Capitalismo tardio ou sociedade industrial?", conferência pronunciada em 1968, encontra-se um trecho com teor semelhante, aliás, ainda mais claro: 
“A dominação sobre seres humanos continua a ser exercida através do processo econômico. Objeto disso já não são mais apenas as massas, mas também os mandantes e seus apêndices" (Adorno, 1986a, p.67). Ora, tais afirmações colidem inteiramente com a tese de Pollock, não apenas por reafirmar a primazia do econômico sobre o político como por ressaltar que mesmo o grupo dominante está sujeito ao processo econômico. Na mesma conferência, o frankfurtiano acrescenta:

A sociedade é capitalismo em suas relações de produção. Os homens seguem sendo o que, segundo a análise de MarX, eles eram por volta da metade do século XIX: apêndices da maquinaria, e não mais apenas literalmente os trabalhadores, que têm de se conformar às características das máquinas a que servem, mas, além deles, muito mais, metaforicamente: obrigados até mesmo em suas mais íntimas emoções a se submeterem ao mecanismo social como portadores de papéis, tendo de se modelar sem reservas de acordo com ele. Hoje como antes produz-se visando o lucro [um des Profits willen] (idem, p.68).

Na última aula de seu curso Introdução à sociologia, também de 1968, Adorno reafirma o predomínio do econômico na sociedade moderna:

Em tais casos, o risco [da perspectiva histórica para a sociologia] consiste em que, através da relação da sociedade ao passado ainda não determinado totalmente pela economia e não tão socializad3o como atualmente, se gera a impressão de que em tempos idos ou até mesmo de um modo geral e em qualquer circunstância, houve o predomínio do espírito na sociedade, e não, como podemos postular para a sociedade atual, justamente o predomínio do nexo econômico, ao qual entrementes também foram integrados os chamados fenômenos espirituais em toda sua abrangência (Adorno, 2008, p.338)

O que se coaduna inteiramente com a tese contida na Dialética negativa segundo a qual "o predomínio da economia não é nenhuma invariante" (Adorno, 2009, p.163), isto é, que a dominação da economia sobre as outras esferas da vida e da sociedade é uma característica específica da sociedade capitalista e não uma "lei geral" ou um princípio metódico a ser aplicado a qualquer situação. Acredito que estas passagens são suficientemente claras para rechaçar de forma enfática a tese da adoção por parte de Adorno do diagnóstico de Pollock acerca do capitalismo estatal e do primado do político.

Não se deve, no entanto, concluir a partir disto que não houve alterações profundas na teoria de Adorno, sobretudo no que se refere ao campo econômico. O fato de Adorno afirmar que, tal como nos tempos de Marx, as pessoas estão submetidas à dominação da economia não deve ser entendido como se com isto ele estivesse subscrevendo a validez de toda a análise marxiana para a sociedade que lhe era contemporânea. Em primeiro lugar, o próprio conceito de "capitalismo tardio"14

140 termo "capitalismo tardio" surge, salvo engano, na obra de Sombart (Der Moderne Kapitalismus, de 1902) e se dissemina ao longo dos anos 1930 e 1940, sendo usado em vários escritos dos autores vinculados ao Instituto (inclusive na Dialética do esclarecimento). Cabe notar que o termo é usado de forma pouco rigorosa, de forma que sua adoção (por Adorno, Habermas, Offe, Mandel etc.) não significa uma adesão a um mesmo diagnóstico. 
é adotado pelo frankfurtiano em grande parte em oposição ao "capitalismo liberal" oitocentista analisado por Marx. Em seu curso Elementos filosóficos de uma teoria da sociedade, de 1964, Adorno elenca algumas modificações que fazem com que não se possa explicar mais "com as fórmulas clássicas de uma sociedade de troca liberal toda a vida social e a reprodução da vida da sociedade" (Adorno, 2008a, p.52), isto é, modificações que violam o "princípio puro de concorrência" (idem, ibidem) e as leis econômicas clássicas. Para começar, o fato do próprio capitalismo liberal se degenerar em monopólios colossais fez com que a sociedade alemã e estadunidense, ao menos, se protegesse com leis antitrustes ou antimonopólio, legislação esta que, não obstante, "tem um momento de ingenuidade" (idem, p.51) uma vez que

a força intrassocial e intraeconômica desse movimento para os monopólios evidenciase ser de uma tal e esmagadora robustez que apesar dessa legislação nem na América nem entre nós deixa-se fazer algo a sério contra essa tendência, sobretudo na medida do desenvolvimento global da técnica e da economia. (idem, ibidem)

Ele menciona ainda o surgimento de medidas como "o intervencionismo estatal, os subsídios aos desempregados e os programas de trabalho público" (idem, ibidem) que "têm instituído de antemão válvulas de escape para a queda, e, portanto, para a crise e para o desemprego em massa" (idem, ibidem); assim como a integração do proletariado à sociedade e a organização do mesmo em grandes sindicatos que faz com que ele consiga negociar uma situação mais vantajosa diante dos grandes monopólios. Segundo Adorno, todas estas modificações foram feitas no intuito de preservar a situação vigente:

Em vista do fato da relação de classes, das tensões de classes, das lutas de classes, que ocorreram, e, ao menos às vezes, da consciência de classe potencialmente disponível, a sociedade em suas formas existentes, a saber, com a propriedade privada dos meios de produção e com o princípio de troca universal, provavelmente não poderia se conservar caso tais modificações não fossem feitas. (idem, pp.49-50)

Destarte, embora não se trate mais, nos detalhes, de uma subscrição à análise marxiana contida em O Capital, nem por isso se trata de um abandono da mesma. É certo que a situação social é outra. O Estado passa a ter um papel cada vez maior de mediação e atenuação dos conflitos sociais. Ao mesmo tempo, o proletariado não só passa a estar integrado, como também consegue obter um quinhão maior da riqueza e com isso satisfazer melhor suas necessidades e desejos. Porém, isto não significa que o objetivo da produção tenha deixado de ser o lucro e passado a ser a satisfação das necessidades e desejos dos viventes (ou, dito de forma mais adorniana, a supressão do sofrimento deles).

Retomando o fio da argumentação: as passagens supracitadas são suficientes para rechaçar de forma definitiva a hipótese segundo a qual Adorno estaria de acordo com a tese de Pollock acerca do capitalismo estatal e, por conseguinte, 
do predomínio do político sobre o econômico. No entanto, tal recusa não significa que o pensador frankfurtiano mantenha-se aferrado à ortodoxia marxista que desconsidera as mudanças ocorridas no campo econômico no decorrer do século XX. Como pode se ver, sobretudo em seus cursos, ele analisou uma série de mudanças estruturais da economia que fizeram com que houvesse uma melhoria no padrão de vida e um abrandamento das contradições internas do sistema capitalista (tanto pelo planejamento e administração estatal, quanto pelo sistema de auxílio aos desempregados etc.), assim como a intensificação da tendência à monopolização da economia. Trata-se, é certo, de um sistema em que o planejamento político, sobretudo administrativo, passa a desempenhar um papel de grande relevância, mas em momento algum este passa a ter a primazia. A administração, e nisto está o ponto central da divergência com Pollock, é ela própria subordinada ao interesse do lucro e é feita até mesmo com o intuito de maximizá-lo em longo prazo. Se Adorno rechaça a teoria de Pollock e reafirma a primazia do econômico, então decorre disto que o campo econômico segue possuindo um papel proeminente como objeto de sua crítica tardia.

\section{A insuficiência da crítica da economia política}

Afirmar que a crítica do capitalismo seguiu sendo necessária não é o mesmo, porém, que afirmar que ela segue sendo suficiente. Neste sentido, não só passa a ser importante ver o quanto foi alterada a própria estrutura do capitalismo, na medida em que o Estado interventor passa a atenuar o caráter destrutivo e autodestrutivo do capital, como também analisar se basta, para uma teoria crítica da sociedade que busque a "emancipação das pessoas frente as relações que as escravizam" (Horkheimer, 1988, p.219), criticar a economia política, isto é, se é apenas o capitalismo o obstáculo que impede a libertação. A resposta é negativa. É preciso não apenas ver o que mudou frente ao diagnóstico traçado por Marx, como ampliar o escopo deste para ver o que mais impede que os homens se relacionem de forma solidária e consciente. Ao menos três aspectos merecem destaque.

Em primeiro lugar, Adorno afirma que Marx adere a um conceito de cientificidade sem "perceber plenamente que haveria que examinar e analisar a configuração da ciência que leva precisamente a marca da sociedade" (Adorno, 1974, p.172), isto é, que Marx é acrítico em relação à ciência moderna, e, por conseguinte, não conseguiu compreender como a própria forma de racionalidade prevalecente na sociedade moderna está amalgamada com o processo que ele mesmo denuncia. Este primeiro aspecto mostra que é preciso ampliar o escopo da crítica marxiana de forma a incluir também a crítica da forma de racionalidade prevalecente; uma forma de racionalidade que contribui para a disseminação do capitalismo ao mesmo tempo 
que é impulsionada por esta.

Em segundo lugar, Adorno acusa Marx de ser acrítico frente à dominação desenfreada da natureza:

Na verdade, em Marx o princípio da dominação da natureza é aceito bastante ingenuamente. De acordo com a concepção de Marx, é preciso mudar algo nas relações de dominação entre as pessoas - elas devem ser transformadas, ou melhor, devem desaparecer - mas a dominação absoluta da natureza pelos seres humanos não é afetada por isso, de tal maneira que se pode dizer que a imagem de uma sociedade sem classes em Marx, como Horkheimer uma vez formulou, tem algo de uma gigantesca sociedade de ações para a exploração da natureza (Adorno, 2003, p.89).

Isto é, é preciso não apenas terminar com as relações de dominação entre as pessoas, mas também colocar limites na dominação da natureza pelas pessoas, refletindo sobre o quanto tal dominação é necessária e como pode ser atenuada. Novamente, isto é uma complementação da crítica original marxiana (e não uma substituição do objeto de crítica, como Jay, Habermas e outros sugerem).

Por fim, é preciso também investigar os motivos que fazem com que "incontáveis indivíduos - e pode-se mesmo dizer: a maioria avassaladora dos homens - agem seriamente de modo contrário a seus interesses racionais" (Adorno, 2008, p.274), de forma que, em vez de lutarem contra seu processo de assujeitamento, contra as condições que os oprimem, eles se aferram a tal processo e a tais condições, em grande parte por meio daquilo que a psicanálise designa de identificação com o agressor. Isto traz a psicanálise para o centro da teoria crítica, para o lado da economia política como foco do interesse. E mais: exige a análise do processo de enfraquecimento do eu, da supressão do indivíduo, condição que coloca mais um obstáculo no árduo caminho em direção a emancipação.

\section{Conclusão}

Em suma, o artigo que ora finda consiste apenas em uma espécie de convite para repensar a teoria crítica tardia de Adorno, uma vez constatadas as graves deficiências de boa parte da literatura que versa sobre ela. Para tanto é preciso ver como as críticas de Adorno ao capitalismo, à forma de racionalidade prevalecente na modernidade, à dominação absoluta da natureza e aos danos e patologias que pairam sobre os indivíduos se entrelaçam e se complementam. Em suma, no presente artigo foi visto que: 1) Adorno, ao menos em suas obras tardias, não adotou a tese do primado do político proposta por Pollock, que de acordo com ele a dominação econômica segue tendo a primazia na sociedade; 2) isto não significa que Adorno se aferre a uma ortodoxia marxista, mas sim que de acordo com ele as mudanças estruturais ocorridas na sociedade desde a época de Marx serviram, sobretudo, para 
manter a dominação econômica, para dar sustentação a um sistema que solapa suas próprias condições de manutenção; 3) que a crítica da economia política seguia sendo necessária para a teoria crítica, mas já não era mais suficiente, uma vez que agora é preciso também analisar o quanto a forma de racionalidade prevalecente está amalgamada com tal sistema; é preciso também criticar a dominação absoluta da natureza e pensar uma maneira de reconciliação para com ela; por fim, ver como as próprias instâncias psíquicas dos indivíduos contribuem para a manutenção da dominação que paira sobre eles, assim como o processo de enfraquecimento da instância designada “eu” por Freud.

Se minha interpretação quanto à rejeição, por parte do Adorno tardio, da tese pollockiana acerca do capitalismo estatal for correta, a teoria crítica de Adorno se torna sem dúvida mais sedutora para leitores contemporâneos. Isto porque os últimos cinquenta anos foram marcados, sobretudo, por uma forte desregulamentação dos mercados e pelo reempoderamento do capital, o que de certa forma solapa a crença no primado do político (e mais, sugere que este primado não foi mais do que aparente no passado recente). Ao mesmo tempo, Adorno nota a criação de válvulas de escape para crises, mas não afirma, como Pollock, que as causas destas estavam potencialmente eliminadas. A crise atual do capitalismo, a qual de forma alguma deve ser vista apenas como uma crise de legitimação (na verdade, o capitalismo se encontrava talvez no ápice de seu sucesso em termos de legitimação quando a crise se iniciou, em 2007), traz de novo ao primeiro plano a dimensão econômica (e mesmo distributiva) em boa parte dos conflitos sociais. Nestas condições, parece-me que Adorno oferece um diagnóstico que sem dúvida precisa ser questionado e modificado, mas mais valioso para se compreender nossa própria época do que os diagnósticos da teoria crítica, do tempo de Adorno e posteriores a ele, que menosprezam o âmbito econômico e seus antagonismos internos em prol da primazia da análise política.

\section{Referências}

Adorno, T. (1974). Philosophische Terminologie (Band II). Frankfurt am Main: Suhrkamp Verlag.

(1986). Ästhetische Theorie. Frankfurt am Main: Suhrkamp Verlag.

. (1986a). “Capitalismo tardio ou sociedade industrial?”. In: Gabriel Cohn (org.). Theodor W. Adorno: sociologia. São Paulo: Ática.

. (1986b). “Gesellschaft”. In: Gesammelte Schriften 10/2. Frankfurt am Main: Suhrkamp Verlag.

(1992). Minima moralia. Tradução de Luiz Eduardo Bicca. Revisão de Guido de Almeida. São Paulo: Ática.

. (1997). “Das Schema der Massenkultur”. In: Gesammelte Schriften 3.

Frankfurt am Main: Suhrkamp Verlag. 
Paulo: Ática.

(1998). Prismas. Tradução de A. Wernet e J. M. B. de Almeida. São Suhrkamp Verlag.

(2003). Vorlesung über Negative Dialektik. Frankfurt am Main: . (2008). Introdução à sociologia. Tradução de W. Leo Maar. São Paulo:

Unesp.

- (2008a). Philosophische Elementer einer Theorie der Gesellschaft. Frankfurt am Main: Suhrkamp Verlag.

. (2009). Dialética negativa. Tradução de M. A. Casanova. Revisão de E.

S. Neves Silva. Rio de Janeiro: Zahar.

Adorno, T. W. e Horkheimer, M. (1985). Dialética do esclarecimento. Tradução de Guido de Almeida. Rio de Janeiro: Zahar. Verlag.

(2003). Briefwechsel (Band 4.II 1938-1944). Frankfurt am Main: Suhrkamp

Benhabib, S. (1986). Critique, Norm, Utopia. New York: Columbia University Press.

Benzer, M. (2011). The Sociology of Theodor Adorno. Cambridge: Cambridge University Press.

Berendzen, J.C. (2013). “Max Horkheimer”. In: E. Zalta (ed.). The Stanford Encyclopedia of Philosophy (Fall 2013 Edition), URL = <http://plato.stanford.edu/ archives/fall2013/entries/horkheimer/>. Acesso em 14 out. 2016.

Bohman, J. (2013). “Critical Theory”. In: E. Zalta. (ed.). The Stanford Encyclopedia of Philosophy (Spring 2013 Edition), URL = <http://plato.stanford.edu/archives/ spr2013/entries/critical-theory/>. Acesso em 14 out. 2016.

Bukharin, N. (1972). Imperialism and World Economy. London: Martin Lawrence.

Cohn, G. (1986). “Introdução: Adorno e a teoria crítica da sociedade”. In: Gabriel Cohn (org.). Theodor W. Adorno: sociologia. São Paulo: Ática.

Cook, D. (2004). Adorno, Habermas and the search of a rational society. Londres: Routledge.

Dews, P. (1996). “Adorno, pós-estruturalismo e a crítica da identidade”. In: Slavoj Zizek (org.). Um Mapa da ideologia. Rio de Janeiro: Contraponto.

Dubiel, H. (1985). Theory and Politics. Cambridge: MIT Press.

Freyenhagen, F. (2013). Adorno's Practical Philosophy: Living Less Wrongly. Cambridge: Cambridge University Press.

Habermas, J. (2012). Teoria do agir comunicativo. Tradução de P. A. Soethe e F. B. Siebeneichler. São Paulo: Martins Fontes.

Hammer, E. (2006). Adorno and the Political. Londres: Routledge.

Honneth, A. (1993). The Critique of power: reflective stages in a critical social theory. Cambridge: MIT Press.

Horkheimer, M. (1975). “Teoria tradicional e teoria crítica”. In: Benjamin, W., Adorno, T., Horkheimer, M., e Habermas, J. Textos escolhidos. São Paulo: Abril Cultural. (1985). “The Authoritarian State”. In: A. Arato e E. Gebhardt (ed.). 
The Essential Frankfurt School Reader. New York: Continuum.

. (1988). “Nachtrag”. In: Gesammelte Schriften, Band 4. Frankfurt am Main: S. Fischer Verlage.

Jay, M. (1988). As idéias de Adorno. Tradução de Adail Sobral. São Paulo: Cultrix, EDUSP.

. (2008). A Imaginação dialética. Tradução de Vera Ribeiro. Rio de Janeiro: Contraponto.

Kellner, D. (1975). The Frankfurt School Revisited: A Critique of Martin Jay's The Dialectical Imagination. New German Critique, 4, pp.131-152.

Marramao, G. (1975). Political Economy and Critical Theory. Telos, 24, pp.56-80.

Neumann, F. (2009). Behemoth. Chicago: Ivan R. Dee.

Nobre, M. (1998). A Dialética negativa de Theodor W. Adorno: a ontologia do Estado falso. São Paulo: Iluminuras.

Nobre, M. e Marin, I. (2012). Uma nova antropologia, unidade crítica e arranjo interdisciplinar na Dialética do esclarecimento.Cadernos de Filosofia Alemã, 20, pp.101-122.

Pedroso, G. (2009). Entre o capitalismo de Estado e o Behemoth: o Instituto de Pesquisa Social e o fenômeno do fascismo. Cadernos de Ética e Filosofia Política, 15, pp.151-179.

(2013). "Capitalismo de Estado ou Capitalismo Tardio". In: M. Carvalho e V. Figueiredo (orgs.) Filosofia alemã: de Marx a Nietzsche. São Paulo: ANPOF.

Pollock, F. (1941). State Capitalism. Studies in Philosophy and Social Science, IX(2), pp. 200-25.

Postone, M. (2003). Time, Labor and Social Domination: A reinterpretation of Marx's critical theory. Cambridge: Cambridge University Press.

Ramos, D. (2012). Franz Neumann e o nazismo como destruição do Estado. Ethic@, 11(3), pp.299-327.

Wiggershaus, R. (1995). The Frankfurt School: its history, theories, and political significance. Cambridge, MA: MIT Press.

Zuidervaart, L. (2011). “Theodor W. Adorno". In: E. Zalta (ed.). The Stanford Encyclopedia of Philosophy (Winter 2011 Edition), URL = <http://plato.stanford. edu/archives/win2011/entries/adorno/>. Acesso em 14 out. 2016.

Recebido em: 01.03.2016

Aceito em: 04.10.2016 